\title{
Musical Communication as an Integral Process
}

\author{
Alexander Yakoupov \\ Russian State Specialized Arts Academy \\ Moscow, Russia \\ e-mail: rgsai@mail.ru
}

\begin{abstract}
In this article the author believes musical communication to be an important part of human life. He specifies three integral parts of this process: a composer, a performer and a music critic. He studies the music process as communication between these three parts. Connection between these parts is determined.
\end{abstract}

Keywords—music communication, music process, composer, performer, music critic

\section{INTRODUCTION}

Considering musical communication as an integral process, it is necessary: first, to find out the ways that information circles create and sustain their integrity; then, to see what the major object of communication is; and finally, learn which transformations the information has to undergo within the system when it moves through the complex and dissimilar chain of the participants within the process of musical communication.

\section{PARTICIPANTS OF THE MUSIC PROCESS}

It has been already mentioned that the major participants within the process of musical communication are the composer, the performer and the musicologist-critic. Their roles in the process are different; they transform the received information to a considerable degree, 'dragging in' their diverse living, aesthetic and musical experience, as well as certain socio-cultural layers.

The material form acts as the major object of the transfered information, which is widely understood as the author's understanding, his original intention. This materialised, specifically encoded communicative form, that acts as the original substrate of the aesthetic message, demands a further decoding (interpretation) by the performer, so that the original idea can be restored to its acoustic form, that is to the natural material and medium of music. It is here that the first 'restoration' of the musical information takes place, whereby the information is restored, though not literally, but in its isomorphic form (that is, it still remains self-identical, but is, nevertheless, transformed to a degree). Such a transformation is unavoidable, since the performer does not only decipher the information, but treats and handles it artistically for his final objective is to get it across to the listener together with his own understanding and attitude. The listener, in his turn, decodes the information received from the performer and constructs upon the basis of that information, using his living and cultural experience, his own version of the music that he later, if indirectly, brings out into the society through his own activity.

At the same time, the musicologist-critic decodes both the composer's and the performer's versions, takes into consideration the evaluation of the listener and creates communicative channels to all the participants of the process and to the public musical consciousness.

One has to note especially that the content of the author's message serves as the 'all-round', general information material here, not quite as much its form. One of the major tasks of the latter is to preserve, through the system of encoding and decoding, the notional and aesthetic content of a musical piece. But here not only the observance of the isomorphic factor of all the communicative chain links is a necessity, but a presence of a clear-cut and definite logic of the musical language, of the expressive means of music, and, in a broader sense, of the whole fabric of musical thought.

Up to the middle of the century, the scientists had largely avoided the issue of the integrity and the content of the communicative process. And it was only in the middle of the century that the works of German physicist, Werner MeyerEppler laid the basis for the general theory of communication which was published in Germany and France. Using the terminology applied to the technical communication links and the cybernetic principles of thinking developed by $\mathrm{C}$. Shannon, the founder of the theory of information "Fig. 1", Meyer-Eppler has developed a general scheme of the communication process that may be concisely presented as follows.

The sender, having studied a certain amount of signs and the signal system that is utilised by a particular socio-cultural group as a whole, takes out a certain number of signs from that general amount, then combines the signs according to the rules established within the given system and transfers the information to the addressee in the form of a certain message using a certain physical channel of communication. The addressee deciphers the whole set of signs and their combinations, compares it with the set of signs he already possesses and thus perceives the message in question. This is the way the process of communication takes place. 


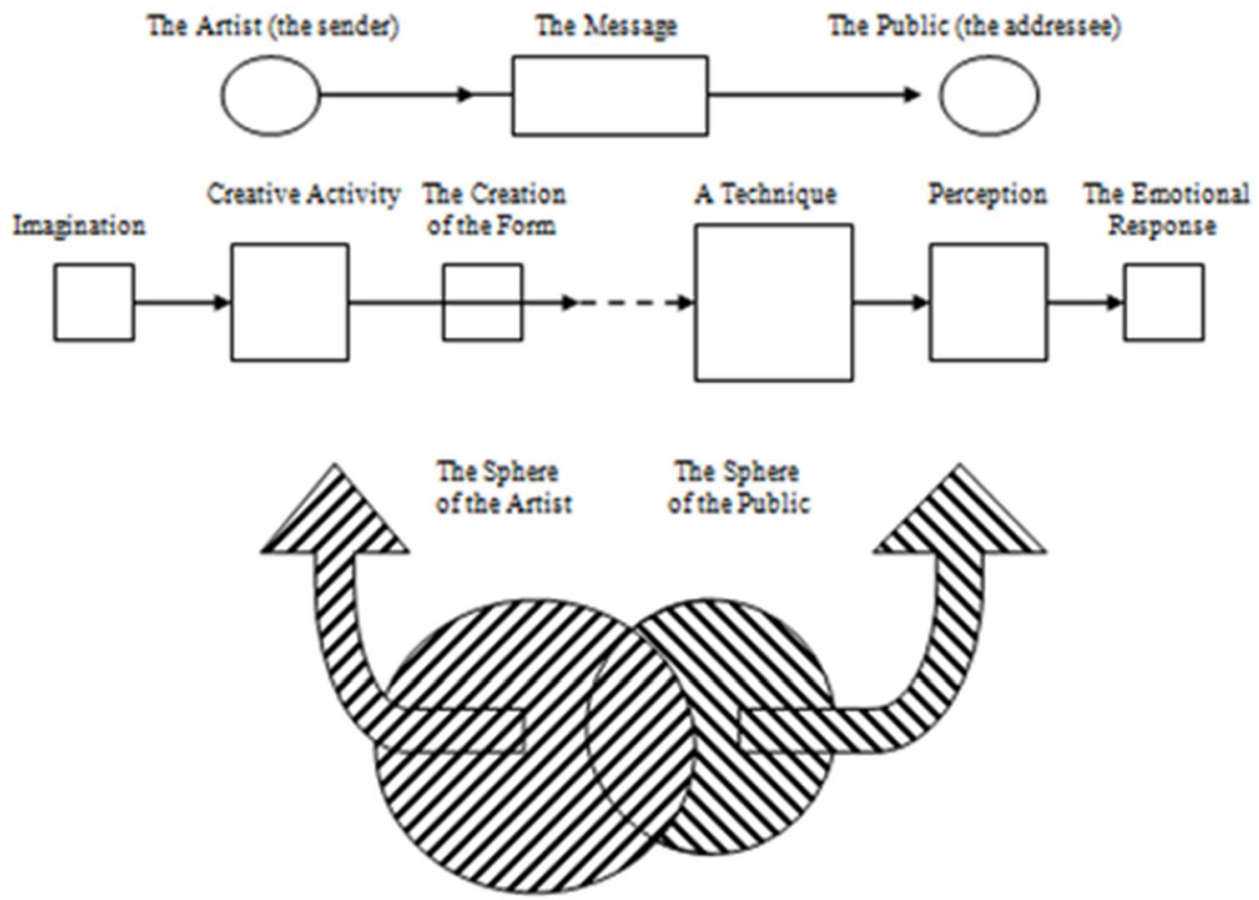

Fig. 1. The basic scheme of the process of aesthetic communication (by A. Moles after W. Meyer-Eppler)

\section{History OF MUsic Process StUdy ING}

According to Meyer-Eppler the transfer of ideas through the communicative channels is only possible provided the signs and the sign systems of the sender and the addressee are identical. When the process of communication is repeated a considerable number of times, the human memory and the capability of the human mind to creates statistical generalisations enabling the learning process. The outcome of which is contained in the condition of 'adequacy' that exists in the sign volumes of the sender and the addressee.

A. Moles, who used the scheme as the principal one in his work, believed that the scheme reflects the essence of the process of perception, both of the technical messages and the information related to the cultural sphere. He wrote, 'In case of an aesthetic message, the author's imagination creates a form or an idea that is then encoded for transmission. The addressee, in his turn, constructs another form or idea. The quality and success of the communicative process is dependent upon the degree to which the perceived and the original forms coincide' $(2,19)$. Graphically, A. Moles presented the process as follows (see chart 1).

The originality and simplicity of the scheme has attracted a number of theorists. The transformation of the opinions on the essence of the communication between the composer and the listener, the fact that the informational theory terminology came to be accepted in musicology - all serves as proof that Moles's ideas were considered quite reasonable. On the other hand, there are serious reasons to doubt the fact that the cited scheme and the related terminology quite adequately reflect the essence of the complex phenomena of the musical art, including its communicative phenomena.

First of all, one has to state that according to Meyer-
Eppler's conceptual scheme all the participants within the process of communication in the sphere of music cannot be represented. The musical art is specific. Even Hegel noted the following, 'Since the sounds themselves are devoid of the lasting objective existence, unlike buildings, statues and pictures, since they vanish after a momentary spell, the musical art, even because of that momentary existence, has to be constantly reproduced and recreated' (3, 295-296).

And it is the performing musician who reproduces the musical form again and again, connecting the author to the listener. But it would have been wrong in principle to identify the performer's aesthetic mission with the function of some transmitting link in the communicative chain, thus leaving him but a passive role. Had it been so, the modern technical media of music reproduction would have forced the actual musician out of the communicative field. In practice, as it is well known, the public is often attracted by the performer, irrespective of the programme that is offered - the public is often attracted by a particular name, it comes to see and hear Pavarotti, or S. Richter, or F. Lips. In this case, some even see an alienation of the author from the communicative process, an unwarranted usurpation of his creative role by the performer.

In fact the great importance of the performer in the communicative process is quite reasonable for it springs from the very nature of music. From the very moment when music emerged as professional art, it exists as a unity of the two processes: that of composing, and that of performing. Music, as it is well known, is a process art. For its deep comprehension both what sounds and the way it sounds are of paramount importance. 'The public comes to a concert to hear one of the most famous symphonies by Tchaikovsky, exactly because it is interested in the way the conductor will treat it, and in the way that treatment will be different from the others' treatment', 
notes D.B. Shafran (cit. according to 4, 148; italics by the present author. - A. Y.).

But how do we place the performer into Meyer-Eppler's scheme? Who is the performer - the second sender? Or a bifunctional component of the communicative process - a sender and an addressee at the same time? The analysis of the performer's activity demonstrates that his function is different from that of the author, although he seemingly conducts what the author actually used to do, or what he must have been doing before the historical division of labour in the musical art took place.

Creating the form of the musical message, the composer materialises on paper, with the help of notation, the ideal image or symbol that his aesthetic mind originally created. While reproducing the sound matter of music the performer moves rather in the opposite direction - towards recreating the original spiritual meanings. But when he deciphers the notes and interprets the sound matter of music, he does not only decode the symbols, he also creates on their basis a new original 'vision' of the ideal image.

Therefore, in the communicative process, the performer comes to act not as an animator of the form and an interpreter, but also as a kind of author for the new, additional meanings. From this viewpoint the seemingly paradoxical idea, that R. Wagner once expressed in a letter to F. Liszt, becomes clear, '.. In fact, it is the performer that acts as a true artist. All our poetic efforts, the whole of our composing work is just a certain statement of I will, not I can. And it is only in the performance that the I can emerges, that the art comes forth' $(5,22$; italics by the present author. - A. Y.). These words are very illustrative for demonstrating the essence of the communicative links that we discuss.

The historical musical practice has seen a considerable number of examples when a certain performer's interpretation provoked the general interest, whereas the performance of the same piece by the author himself failed to do just that. Say, S. Prokofiev and D. Shostakovich, wonderful performers themselves, both refused, at a certain point in their creative careers, to 'combine the functions', and entrusted the first performance of their piano pieces to prominent pianists.

For instance, V. V. Sofronitsky was one of the first performers that offered an original interpretation of Prokofiev's music, as compared to the interpretation by the author himself. As early as in the 20s, at his concerts in Russia and abroad, he started, in accordance with his aesthetic credo, to actively explore the lyrical nature of the music, trying to establish the line of continuity between Prokofiev's art and the general spiritual direction of the national musical culture. Another example: at a Moscow concert in November of 1940 S. Richter brilliantly performed Prokofiev's Sixth sonata (op. 82) and audaciously contrasted the lyrical and poetic episodes with the paganistic, the Scythian images that were considered traditional for Prokofiev's art. The subject basis of the piece was therefore disclosed through the confrontation of the two polar essences - the cruel expressiveness and the subtle lyricism. Thus the performer provoked the genuine interest of the public towards that particular piece (see 6).
It is noteworthy that the mentioned performance had been a few months before preceded by a radio broadcast of the same sonata performed by Prokofiev himself. That broadcast did not at all make a sensation. The prominent musicologist V. Delson has noted on the subject, 'One might presume that in the final phase of his concert activity Prokofiev was already dissatisfied by the character of his performing style. This probably accounts for his statement that when his works were performed by some of the first-rate pianists (S. Richter, E. Gilels) he was "quite satisfied" and even "came to see his own work anew, as if in a new light"” $(6,98)$.

It is interesting that this ability of 'the pianist of the century' to create remarkable performing concepts (not just versions of the same piece, but, exactly, aesthetic concepts) was explored in L.Y. Gakkel's famous article with the intentionally paradoxical title Beethoven's Richter (7). Well, taking the above into consideration, let us come back to the structure of the process of musical communication.

The cited scheme by Meyer-Eppler has no place for the necessary participant of the musical communication - the musicologist-critic. And it is that participant that plays the central part of forming the public musical consciousness, therefore, he fulfils the most important, the managing function in the process of musical communication. He is, doubtlessly, one of the most important participants in the communicative chain 'the author - the performer - the listener', since his activity is involved in each of the cited links, it significantly influences the dynamics of their interaction. Therefore, the musicologist (as well as the performer) is a rightful and active participant of the process of musical communication. That is why, in relation to music, the scheme by Meyer-Eppler has to be significantly corrected (see chart 2).

Let us now touch upon the important issue of using the information theory terminology in musicological studies. For clearing up the issue, we deem it advisable to first single out one of the key terms, then consider its notional aspect by trying to explicate it, and then to study the very subject that it denotes and the place of the latter in the process of musical communication.

A. Moles helps to resolve the problem of choosing a term he often uses the term 'message' as a synonym to the term 'a musical piece', since he believes that the message 'is the basic element of the communicative process' $(8,18)$.

A. Moles defines the term as follows, 'a message is a finite and ordered set of the elements of perception, that are taken from a certain set and joined into a structure' $(9,40)$. The theorist treats a message as a materialised form - an information carrier/medium. Here he demonstrates his abidance by Shannon's principles whose theory is characterised by finding the content of the information through the precise measurement of the amount of physical information received during a given time period. This theory is of a clearly abstract character for it fails to consider the notional aspect of information, its value level. Shannon's theory of information is aimed at realising the statistical probability approach, and this fact has an explanation - the theory emerged as an instrument of solving the technical problems of communication and was related basically to studying the throughput capacities and static resistance of the 
technical, material channels of information transfer.

It seemed that Moles realised the weaknesses of applying the theory of information to the aesthetic sphere. Thus, he introduced such additional notions as the 'semantic information' and 'aesthetic information'. But in practice he still applied the same physical measurements. Suffice it to say that the first of the mentioned notions he reduced to a certain set of the commonly used standard signs and the second - to the variations in the accepted deviations of the signs from the norm. He also suggests a system of measuring the both, a system based on the degree of originality, unpredictability of the deviations, again, in the physical, formal aspect. Thus the notional, the spiritual essence comes to be regarded as a derivative of the material essence, as dependent upon the latter.

In short, we deem it appropriate to revise the attitude towards A. Moles's theory of aesthetic information. It should not be regarded as all-embracing, since it is just a local theory that discloses the whole only in one of its aspects. That is, it discloses (but partly, at that) the meaning and influence of the physical, material values in art.

The classical (academic) musicology does not use the term 'message' in the sense of musical content expressed through an adequate form. It uses the traditional terms of the 'musical piece' and 'musical form'. We should also note here that even a century ago (and even much later) the term 'musical form' was only applied to define a certain type of composition. But for the last fifty years it has been used in a different, much wider sense.

Thus, B. V. Asafyev, for instance, defined the semantics of the piece not as a reflection of the architectonic silent schemes, but as an orderly process of the sound materials organisation and crystallisation. 'Let it be the crystallised form of the sonata allegro, or the scheme of cadences, or the formulas of harmonies or scales - all of that conceals the lengthy process of searching for the best means and trying to arrange them for the most 'understandable' expression, searching for the intonations that would be most productively perceived by the environment through the forms of musical performance' $(10,21)$. This statement proves that, although Asafyev gives the tradition its due respect in regarding the musical form and considers the latter as a certain typified structure; he greatly widens the types' boundaries.

\section{MOdern Musicology AND ITS AdvocAtes}

The modern musicologists, in their turn, utilise the term in still a broader sense - as a certain content expressed through sound, not necessarily having a typical structure. That is the approach that V. V. Medushevsky advocates in his work (see, for instance, 11, 115-117, 132-133, etc.).

The notion of 'a musical piece' is often used in musicology to define a concrete, finished and exclusive content of music, whereas the term 'musical form' is often utilised in a broader sense - from denoting a structural part of such an integral entity, to the whole itself, it is also used to indicate a certain system of musical expressive means as an object of theoretical research, abstracted from any concrete content. In spite of the established polysemy of the term (it may also denote the individual sound contours of a piece, the aesthetic regularity of the musical composition, etc.), one cannot fail to notice that this polysemous tendency has not influenced the study of the musical form as an object of philosophical cognition. Particularly, if it is considered through the interrelation of the categories of form and meaning their integrity.

In musicology the categories are traditionally understood as a terminological pair that reflects the original interrelation of the two aspects - the natural and semantic, the material and the spiritual, the structural and the notional. It is known that even the smallest particle of musical content is often accounted for by a complex formative combination of the musical means. And vice versa - not a single formational structure exists without an appropriate meaning. The appearance of even a single new tinge of meaning cannot take place without some change of the formal, the sound aspect. And even the most insignificant transformations of the form influence the meaning immediately. In this respect, both the categories are equal. There is no chance to define any priority among them.

Those relationships are especially noticeable in performance (the central element of the communicative process), and at the small scale level at that, as it was clearly demonstrated by O. Y. Sakhaltuyeva and Y. V. Nezaikinsky who undertook an acoustic analysis of the subtle nuances of intoning Schumann's Dreams by three prominent instrumentalists (see 12).

In the case of a message, if it comes to be regarded as an information carrier (according to A. Moles), the acceptable transformation in form does not always lead to a change in meaning. Thus the gist of the information would remain the same if, say, the Gothic script is changed into some ornamental ligatured one, or a phrase is first pronounced in at a low pitch and then at a high, first slowly - then rapidly, etc.

The same situation is impossible in music. If The Cuckoo by L. Daquin, created in the sound imitation manner characteristic of the harpsichord musicians, is conducted in the 'Gothic' style of I. S. Bach (that is, when the deviations analogous to the above example are introduced) without any change in the authors pitch and rhythm, the content, the aesthetic meaning of that expressive miniature will change perceptibly.

The examples that bear witness to the above ideas may be encountered daily. Say, when in our sound environment we hear the music of the old masters styled like rock or various other contemporary genres. Formally preserving the author's text, but influencing the form by breaking the performing traditions and the established style of intoning, changing the character of articulation, the timbre nuances, etc., the modern 'interpreters' of the classical music sharply distort its content.

At the same time, according to A. Moles's methodology, a 'message' may be presented not as a synthesis, an aggregate of form and meaning, but as an object with local form and meaning. But in music the form and the meaning are naturally inseparable, and we consider this fact the demonstration of a major discrepancy between the cited theorist's position and the way that matters actually stand.

Taking into account the considerable discrepancies between 
the terminology of the theory of information and musicology, we deem it appropriate to use the terminology of theoretical musicology while studying the musical communication, since that particular terminology better reflects the essence of the phenomena under consideration. Say, it would be helpful to replace the category of 'the quality of musical communication' that A. Moles uses with the notion of the depth of the process of musical communication, thus stressing the vertical of meanings that constitutes the process. One should also bear in mind that according to the cited theorist the quality of the process is measured by the degree of adequacy (coincidence) of the form - the addressee's perceived form and the sender's original form. Let us try to see how matters really stand here.

\section{THE VARIETY OF MUSIC FORMS}

The musical form may be considered in its latent condition (its condition of tranquillity), say, when it is a noted text on paper or when it is stored in the memory of a computer, etc. Then it definitely possesses a complex of original parameters, whose aggregate bears a certain amount of information. But in notation this information reflects only the pitch, the rhythmic, the timbre and dynamic, etc. The spiritual aspect of the form in that case exists only potentially, it can only be realised in reproducing the whole form in its integrity. But when the appropriate reproduction starts, a new paradox arises. Together with the reproduction of the author's premises and of the original information, an additional attitude to those premises is realised, that is, an interpretation of the potential information takes place.

While recreating the original form, every performer may only do it taking into consideration the way he himself understands and feels the mentioned premises, in accordance with his own professional and personal characteristics. Reconstructing the original ideal image in his mind he cannot reproduce it with complete precision, even if he strives to. Neither can the author himself. Although the author may better fathom the spiritual, the notional aspect of music, and his own authorised rendition may be of special value (as a second authorised text), he is still bound by the expressive means at his disposal. In this respect the author is akin to any performer and becomes, to a considerable degree, another interpreter of the original form, even though he was the one who created it.

The above is proven by the fact that an author (as well as a performer) is unable to perform the same piece twice in the same detail and reproduce the same musical form twice in an identical manner. M. P. Moussorgsky, for instance, was forced to specifically learn his own work for public performance. Therefore, the original form in its notional aspect exists in the author's mind as an ideal image. While reproducing it, he transforms it, in spite of himself, because of the limitations of his own performing capabilities, the instruments he uses, etc.

So, when the ideal image is transformed, the author changes the information he gets across to the listener, too. Therefore the author's form itself cannot be considered as uniform, fixed or a static phenomenon. Let us consider the issue in slightly greater detail.

The author's form in music may exist in two variants - the complete and the contracted (reduced). So, during the baroque and early classicism periods the slower parts of sonatas were fixed in the contracted means of notation. There was a whole epoch of ciphered bass. Some of the modern aleatoric music gives relative latitude to chance, when the notes fix just the direction of the sound and pitch movement, the time scale, limits of the rhythmic structures, etc. While a more detailed kind of notation provides for a relative stability of the author's form, the contracted notation makes the form dynamically mobile, variable.

Therefore, in the communicative process, the two mentioned kinds of the author's form play different parts, defining the different depth of the communicative processes. The second kind calls for a more active participation of the performer in the artistic process of deciphering the physical layer of the form - it practically demands that the form is actually created anew. The modern practice of the kind spurs the public interest towards the seemingly known, old repertoire, providing the latter with a new acoustic shape (say, when the antique instruments are used), thus the old pieces are given new life.

If the musical form comes to be considered as a communicative object, one might distinguish several essential factors that are directly connected with the optimal realisation of the process of communication. One of those factors is termed as 'the form's being directed towards the listener'. The factor includes a whole complex of the means and techniques that enable the listener to most effectively organise his perception of both the form and the content of music.

For instance, in such a complex form as the sonata allegro, the introduction bears an especial importance for tuning the psychological condition of the listener for it helps him anticipate the coming musical events. And the final part finishes the exposition and marks the transition to another facet of the compositional form - the development. The importance, which the composers assign to the preparation of the main culmination and the pronounced transition towards the reprise, is well known. The code, with the help of a sharp change in tempo, the manner of performance and other expressive means, gives the listener a signal to sum up in his perception the development of an integral form.

Often, say, in Prokofiev's music, the shifts in harmony and style signal a change of the aesthetic environment, the stop of the time flow of the events - the shifts that are associated with an intrusion of the evil forces or a flight to the crystal dreams of the childhood. In S. Richter's, E. Gilels' performance those moments stand out as the special, the key ones - the moments that can arrange the main venues and lines of the content development in the mind of the listener. The culminations, in their turn, stress the three level structure: the light and noble nature - the man - the evil forces - the structure that is so characteristic of Prokofiev.

The first structural category is directly related to the special performer's approach towards creating the actual sound integrity - the constructive principle of realising the form. According to the principle, the performer develops the plan of treating the piece, marks the basic steps in unfolding the musical form. He strives to prepare the listener to the most difficult parts of the way - the shifts of the tempo, the changes 
in timbre, the extension of the phrase endings and other expressive means of performance. Thus, the performer creates a carrying wave of perception that assists the listeners in appreciating all the facets of the musical form, of the structure of the musical drama, and in eventually in fathoming the aesthetic concept of the whole integrity of the piece.

D. F. Oistrakh noted in this respect that in the performers and then listener's interpretation of the form, the strong, colourful, thoroughly elaborated realisation of the main aesthetic idea is of paramount importance. Glenn Gould, for his part, stressed that it was very important for the treatment of Bach's pieces that the listener should be prepared for any introduction of a new theme, to the moment of a change in style and manner of performance, to the beginning of the organ point, stretto, etc. I. S. Bezrodny similarly pays special attention to the psychological justification of any significant change in the flow of music.

The other structural factor, on the contrary, is related to 'hiding the form' from the listener. The process takes its integral shape when it is conducted as an improvisation, when it spontaneously reflects the flow of the human thought, etc. Here the composer and the performer construct the form retrospectively not prospectively. The future steps are not exposed; moreover, an attempt is made to hide them to sharpen the unexpected, the unpredictable effect. With this type of communication the performer should make the listener think that the performance is created right at the moment, at that very time, in that very place. This helps in creating a specific 'presence effect', the impression of the listener's active participation in the creative process, when the listener's anticipations are most active - and that empowers the listener's and the performer's mutual creativity.

To a degree, this principle may be utilised within constructive approach, when a performer is willing to hide some facets of the cyclic form or create an atmosphere of suspense and uncertainty. Say, the Chaconne from I. S. Bach's Partita in $d$ minor for the violin solo may be performed in a constructive manner, when the different variations are separated, or it may be performed in a totally different manner - in a single flow as a great intense phrase (this is the way that this prominent work was performed by J. Heifetz, L. Kogan, I. Bezrodny). It is according to this principle that The Carnival by Schumann, Corelli's Folia, The Variations by Brahms and other cyclic pieces are often performed.

The very choice of the communication type depends on the performer to a considerable degree - the author's texts provides numerous opportunities for it, the opportunities contained in the musical form itself. This way the performer sets a dominant for the listeners' perception, as though letting them choose this or that way of recreating the invariant, without predetermining the creative process of listening that can, in an original manner, combine both the principles.

Therefore the significant aspect of the original form does not have any sharply defined boundaries and or bear any kind of fixed and certain aesthetic information. So, A. Moles's formula for measuring the quality of the communicative process cannot be applied to music. But how should then the quality of musical communication be defined? We believe that it should primarily be defined by the relationship of the creative activities of the four subjects of the process: the author, the performer, the listener and the musicologist/critic. If we accept the author's form as stable and relatively unvaried in quality (except the cases when the author's text is differently decoded) - then the activity or passivity of the performer and the listener add up to the four degrees of the quality of communication.

\section{Four DEGREES OF COMMUNICATION QUALITY}

The first degree. The listener receives the aesthetic information in its physical aspect through the author's form, and in its spiritually significant aspect through the form's interpretation (therefore, it is traditionally said that the invariant and the variant are perceived). The fact that the listener is capable of differentiating the two flows of information is proven by his ability to separately evaluate the author's creativity (or, the original physical form) and the performer's interpretation. Perceiving the physical aspect of the musical form the listener is able to create his own variants (or variations) of the meaningful aspect in accordance with his previous experience and the rules of the system that he absorbed. It is possible because of the apperception mechanism and the anticipating activity of the mind. And if the author's variant provides such an opportunity whereas the performer's interpretation fails in this respect (that is, the suggested variant fails to persuade) - then a deep quality of the communicative process cannot be reached. The listener may then just evaluate and compare the two variants.

The second degree. Unless the performer's interpretation prevents the listener from concentrating upon the physical form, the depth of the communicative process increases to a degree. Here, a whole lot depends on the listener, since the communication is basically conducted through the physical aspect, whereas the spiritual aspect related to the interpretation is insignificant. The performer just reproduces the original form without betraying his attitude towards it, leaving the major work to the listener. This is the so called 'objective performance'.

The third degree. The quality of the perception, and, therefore, the active character of the communicative process, increases in case the performer begins to create lively and strong images in the meaningful aspect of the form, that is, when he starts actively interpreting the latter. The listener may be satisfied while following the course of the performer's interpretation. But, while remaining just a passive perceiving subject, he simply adopts the performer's interpretation, and, therefore creates just an illusion of his own creative activity. This kind of process structure fails to produce the highest degree of the communicative depth, since there are only two active participants - the author and the performer.

The fourth degree. The highest stage of the process depth when the original form and the strong lively interpretation together spur the listener's creative imagination. Thus the apperception mechanism enables a new creative variant of the meanings to emerge in the listener's mind.

The practical concert experience proves that the listener is capable of creating an individual variant of the aesthetic meanings. The talented performers, trying to stimulate the 
listener's imagination, always take into consideration the specific characteristics of musical perception and strive to create the optimal conditions for the work of the listener's mind. This is manifested in picking the concert repertoire, choosing the time to perform a certain piece within a concert and even deciding on the length of the pauses that should separate the pieces in concert. So, many prominent conductors, on finishing the dynamic and impetuous third part of Tchaikovsky's Sixth symphony, made a long pause before the forth part. This was necessary, so that the strong images, or, rather the listener's variants that emerged on hearing the Scherzo, could become more or less settled and complete.

It is known that when the music is over, its images persist in our mind for quite a long time. The imaginative thinking, the sensory and the short term memory, as well as the impression produced by the music, may for a certain brief period augment the dynamic quality of the listener's imaginative processes. The psychological mechanism of the so called interiorising - the folding of perception - takes place. Thus, after the last chord or sound the listener, largely subconsciously, in a very condensed way, relives the meaning of a piece. Therefore time is needed for the creative imagination of the listener to stop 'pulsing', for the listeners' variant to take a finalised shape.

So, Pankevich distinguishes the final phase of the perception process - the aesthetic impact of a piece 'that does not end with the contact period, but is revealed later in all its complexity within the space of the mind and the time of the human life. The process of the social adoption of the aesthetic activity is the process of its entering the culture, its being retained there, the process of augmenting its impact' $(13,71)$.

To enable this stage of information processing, the musical piece itself, as well as the performer's form, contain the communicative structures that assist in both perceiving the information of the same order and transferring it into other information levels, as well as in 'retaining the very mechanism of the transfer in the memory and in expanding it upon a wider scope of phenomena' $(14,6)$. This is the way the communicative process enters the society, influences the creator and integrity and the gradual development of the whole musical process.

And vice versa, the attaca technique is used between the parts of a piece in situations when the author or the performer are trying to manage and direct the listener's perceptive process, striving to create a thorough impact by connecting the images of the different parts of the piece. So, to create an integral impression of a certain actual event, the performers of the Pictures from the Show by Moussorgsky often use the attaca technique between The Walk and the separate numbers.

All the above leads to the conclusion that the process of communication is neither homogeneous nor uniform. This fact is reflected in the cited number of the degrees of the process. And if the first (the initial degree) only implies the coincidence of the author's and the listener's form, the second already demands some creative activity on the part of the listener, and the third is related to the lively original interpretation by the performer as a factor of activating the listener's creativity. The fourth, the highest degree of the quality of the communicative process is measured by the combination of all the three aspects: the author's form that stimulates the performer's interpretation and the creation of listener's variants of the original author's form.

Therefore, the criterion of the quality of the communicative process is not contained in the coincidence of signs, but in the depth of going into the spiritual content of the piece, in the ability of the person who perceives the musical information to create his own meanings for that information.

We can cite a number of considerations that can serve as proof of the above conclusion. First, an ordinary informative message, in case it is adequately perceived by the listener and the addressee (that is the appropriate signs and symbols coincide), does not call for its repeated reproduction. The case of a musical 'message' is different, more complicated in principle. We might note that certain music lovers are prepared to listen to the same well known piece over and over again. There is only one explanation for that: the particular musical form and its interpretation excite the listener and actively stimulate his or her aesthetic imagination.

Second, had the quality of communication been defined by the degree to which the original and the perceived form coincide, all the music lovers and professional musicians who absorbed, say, the system of European music would have made up, in relation to musical communication, a single group. But it is well understood that the historical facts bear quite a different testimony.

\section{CONCLUSION}

The process of musical communication cannot be a uniformed finished cycle until the author and the performer are able to fully evaluate the listener's reaction to the original form. The reaction is not only materialised in the listeners' applause, or in the way this or that concert fares at the box-office, in the preference that is shown towards certain performers or programmes. The reaction is fixed in the musical consciousness of society, it's demonstrated through certain traditions of performing and perceiving, manifested in the critical reviews, listeners' discussions and remarks, in the transformations of the public tastes and in many other aspects of the everyday musical life.

\section{REFERENCES}

[1] SHANNON, C. E., WEAVER, W. The mathematical theory of communication. - Illinois, 1949.

[2] MOLES, A. The Art and the Computer // The Art and the Computer / Moles, A., Fuchs, W., Kassler, M., - M., 1975. - P. 15 - 278.

[3] HEGEL, G. The Aesthetics: Collected Works.: In 4 vols. - M., 1973. - V. 3.

[4] TSYPIN, G. M. The Man, the Talent, the Work. - M., 1992.

[5] WAGNER, R. The Letters, Diaries, Epistles to Friends / Collected works. - Saint-Petersburg,1911.V.4.

[6] DELSON, V. The Problems of Performing the Piano Pieces by Scriabin and Prokofiev // The Issues of Musical Performing. - M., 1962. - Issue 3. - P. 64-123.

[7] GAKKEL, L. E. Beethoven's Richter // Soviet Music. - 1975. - \# 7. P. 59-63.

[8] MOLES, A. The Art and the Computer // The Art and the Computer / Moles, A., Fuchs, W., Kassler, M., - M., 1975. - P. 15 - 278. 
[9] MOLES, A. The Theory of Information and the Aesthetic Perception. Translated from French. - M., 1966.

[10] ASAFYEV. B. V. The Musical Form as a Process. - L., 1971.

[11] MEDUSHEVSKY. V. The Intonational Form of Music. - M., 1993.

[12] SAKHALTUYEVA, O. Y., NEZAIKINSKY Y. V. Upon the Interrelation of the Expressive Means in Musical Performance (upon the analysis of the Dreams by R. Schumann) // The Musical Art and Science. - M., 1970. - Issue 1 - P. 59 - 94.

[13] PANKEVICH G. I. The Sounding Images. - M., 1977.

[14] PANKEVICH G.I. Certain Methodological Problems of Studying the Aesthetic Process. - Saratov, 1985. 